\title{
Metronomic Chemotherapy in Metastatic Breast Cancer
}

\author{
Selma Sakhri* \\ Medical Oncology Department, Algeria
}

\section{ISSN : 2688-836X}

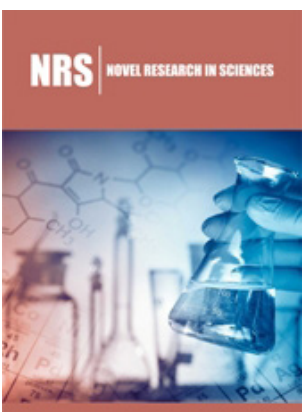

*Corresponding author: Selma Sakhri, Department of Medical oncology, Algeria Hospital, Algeria 10 rue docteur saadane, Algeria

Submission: 監 June 10, 2019

Published: 㘹 June 11, 2019

Volume 1 - Issue 1

How to cite this article: Selma Sakhri. Metronomic Chemotherapy in Metastatic Breast Cancer. Nov Res Sci.1(1). NRS.000505.2019.

DOI: $10.31031 /$ NRS.2019.1.000505

Copyright@ Selma Sakhri, This article is distributed under the terms of the Creative Commons Attribution 4.0 International License, which permits unrestricted use and redistribution provided that the original author and source are credited.

\section{Keywords}

Low-dose metronomic chemotherapy; Metastatic breast cancer

\section{Editorial}

Metronomic chemotherapy is an emergent treatment schedule in which low doses of cytotoxic agents are given orally continuously, with no or short drug-free intervals. In general, it provides better tolerance, especially in patients who have been previously exposed to other oncologic treatments. It is well known that all these low-dose schedules have a favorable safety profile and may provide an adequate tumor control in patients with metastatic breast cancer.

We retrospectively analyzed 11 patients with metastatic breast cancer treated with low doses of Cyclophosphamide and /or Methotrexate and /or Capecitabine in medical oncology department from January 2017 to January 2019. The expression of estrogen and progesterone receptor and HER2 are identified by immunohistochemistry technique. We have evaluated the number of lines of chemotherapy prior to and after low-dose metronomic treatment, and duration of metronomic treatment.

The median time on metronomic chemotherapy was 7 months. The most frequent drugs administered were capecitabine, cyclophosphamide, methotrexate in association or alone. Asthenia, myelotoxicity, gastrointestinal symptoms and hand-foot syndrome were the most commonly recorded treatment related toxicity. Although patients who developed toxicity to low-dose metronomic chemotherapy remained less time $(<2$ months $)$ in subsequent chemotherapy.

We report the efficacy of low-dose metronomic regimens and the tolerance to subsequent lines of treatments following a period of metronomic chemotherapy. Most of our patients were able to tolerate conventional chemotherapy regimens administered in full doses. Several patients received as many as three lines of additional chemotherapy for periods that exceeded 12 months of treatment, which suggests that the use of prolonged metronomic treatment does not affect a patient's ability to tolerate subsequent therapy. 